type (including the use of depot preparations) and characteristics of the clinician, treating team or service. Inevitably, a study that took these factors into account would be restricted to one or two services with consequent loss of statistical power and the dangers of selection or referral bias. Furthermore, our study was able to adjust for more service use confounders than others that have shown positive effects of compulsory community treatment (Bindman, 2002).

However, we disagree that patients who had been discharged from a CTO by a Mental Health Review Board would be a more appropriate control group. Even with careful matching, there would be a reason why the intervention group remained on a CTO while the controls were discharged from their order. For instance, patients who remained on compulsory community treatment could have been less insightful about their illness or more likely to have a history of aggressive behaviour. Neither can we accept that surveys of psychiatrists' views on CTOs have any place in an era of evidence-based practice. This would not be accepted as a reason to introduce any other psychiatric intervention. Why should CTOs with their attendant implications for the civil liberties of patients be treated differently?

Bindman, J. (2002) Involuntary outpatient treatment in England and Wales. Current Opinion in Psychiatry, $\mathbf{1 5}$ 595-598.

S. Kisely Department of Psychiatry

Dalhousie University, Abbie J. Lane Memorial

Building, 5909 Veterans Memorial Lane, Suite 92II, Halifax, Nova Scotia B3H 2E2, Canada

\section{Learning disability services}

Bouras \& Holt (2004) propose a bold solution to a frustrating problem: in a socially inclusive post-institutional society, how should the mental health needs of people with learning disabilities be met? Valuing People (Department of Health, 2001) encourages learning disability services to support access to mainstream services, and only provide specialist services to a minority with particularly complex needs. Their idea of a tertiary level service within adult mental health is, therefore, attractive, although probably more so for people with mild learning disability. Individuals could initially use the same service as everyone else and only be 'referred on' if clinically necessary.
But what would this service look like? What, in fact, are the specialist mental health needs of adults with learning disabilities? When do these needs require a specialist learning disability mental health service? If you have a mild learning disability and a new psychotic illness should you go to the 'first-episode psychosis' team, the 'home treatment' team, the 'assertive outreach' team, the 'long-term intervention' team or the 'specialist learning disability' team? What would be 'special' about the specialist learning disability service? It is not only about being 'secondary' or 'tertiary' but finding a way to participate in a new mixed economy of 'mainstream' services, where the number of potential interfaces has grown considerably in recent years.

General psychiatrists often look after mental illnesses in people with mild learning disability and do so extremely well. However, if learning disability psychiatry aspires to tertiary status it will be important to respond to those who will rely on it. This is not just the potential patients, but also staff of the mainstream services who will refer them. In my local service, colleagues want recognition that although some of their patients fall outside traditional eligibility criteria for learning disability services, they would none the less benefit from such services and should have equity of access the other way.

Bouras \& Holt propose a new, probably rebranded, subspecialty within adult mental health. This has significant implications not just for the National Health Service, but also for the local authorities and other agencies with which it will work. I hope their views will stimulate wider debate.

Department of Health (200I) Valuing People: A New Strategy for Learning Disability for the 2lst Century. London: Stationery Office.

Bouras, N. \& Holt, G. (2004) Mental health services for adults with learning disabilities. British Journal of Psychiatry, 184, 291-292.

A. Flynn Oxleas NHS Trust, 183 Lodge Hill, Goldie Leigh, London SE2 OAY, UK

\section{Psychosocial factors in the pathogenesis of mental disorders}

In an interesting Editorial, Leon Eisenberg (2004) discussed the possible impact of the recent advances in genetics and genomics on social psychiatry. He suggested that these advances, instead of diminishing the importance of social psychiatry, will instead enhance it.

In this context, psychosocial factors may be important environmental factors in the pathogenesis of primary (idiopathic) mental disorders. Several lines of evidence suggest that the primary mental disorders are a product of the evolution of the human brain and mind (Abed, 2000; Peedicayil, 2001). Among the many hypotheses proposed to explain this evolution, the most plausible is the social brain hypothesis, which has also been referred to as the Machiavellian intelligence hypothesis (Dunbar, 1998). According to this hypothesis, the human brain, especially the neocortex, evolved to the relatively large size it has because of the computational demands of the complex social system of primates.

Epigenetics (heritable changes in gene expression that occur without a change in DNA sequence) is thought to have played a major role in the evolution of the human brain (Rakic, 1995), and it is known to involve marked environmental inputs (Strohman, 1997). Hence, by extension, psychosocial factors may be important environmental factors in the pathogenesis of the primary mental disorders.

Abed, R. T. (2000) Psychiatry and Darwinism. Time to reconsider? British Journal of Psychiatry, 177, I-3.

Dunbar, R. I. M. (1998) The social brain hypothesis. Evolutionary Anthropology, 6, 178-190.

Eisenberg, L. (2004) Social psychiatry and the human genome: contextualising heritability. British Journal of Psychiatry, 184, I0I-103.

Peedicayil, J. (200I) The importance of cultural inheritance. Medical Hypotheses, 56, 158-159.

Rakic, P. (1995) A small step for the cell, a giant leap for mankind: a hypothesis of neocortical expansion during evolution. Trends in Neurosciences, 18, 383-388.

Strohman, R. C. (1997) Epigenesis and complexity. The coming Kuhnian revolution in biology. Nature Biotechnology, I5, 194-200.

J. Peedicayil Department of Pharmacology, Christian Medical College, Vellore 632 002, India

\section{Form-content dichotomy in psychopathology}

We read the article on dhat syndrome (Sumathipala et al, 2004) with interest. The apparent disappearance of the syndrome in the Western world and its persistence in the East can be explained by the form-content dichotomy related to psychopathology. Typically, patients with the 